\title{
Exploring individual and social learning in jackdaws (Corvus monedula)
}

\author{
Ira G. Federspiel ${ }^{1,2} \cdot$ M. Boeckle $^{3,4}$ - A. M. P. von Bayern ${ }^{5,6,7} \cdot$ N. J. Emery ${ }^{8}$ \\ Published online: 30 May 2019 \\ (C) The Psychonomic Society, Inc. 2019
}

\begin{abstract}
Information about novel environments or foods can be gathered via individual or social learning. Whereas individual learning is assumed to be more costly and less effective than social learning, it also yields more detailed information. Juveniles are often found to be more explorative than adults. Still under the protection of their parents, this allows them to sample their environment in preparation for later in life. We tested individual and social learning in jackdaws (Corvus monedula) of different age groups in a semi-natural group setting. Juvenile and adult jackdaws differed in their learning propensity. Juveniles spent more time at the test apparatus, were more explorative, and caused the apparatus to open. Almost all the openings at the apparatus matched the demonstrated method. As more observers became available, the juveniles could observe each other. Individuals preferentially watched successful conspecifics and those they could scrounge food from. Lower-ranking individuals tended to watch higher ranking ones; higher ranking individuals preferentially watched conspecifics of similar rank. The control group did not manipulate the apparatus. Due to the lack of this baseline, it was difficult to determine for certain whether the opening technique was acquired via individual or social learning. We conclude that if social learning played a role, the underlying mechanism was most likely local or stimulus enhancement. It is, however, more parsimonious to assume that juveniles were more explorative than adults, and that their opening technique was potentially easier to acquire than the one demonstrated to adults.
\end{abstract}

Keywords Corvid $\cdot$ Jackdaw $\cdot$ Social learning $\cdot$ Individual learning $\cdot$ Age effect $\cdot$ Exploration

\section{Introduction}

When exploring novel foods, objects, nest sites, or predators, information can be gathered via individual or social learning (Reader \& Laland, 2003). The mechanisms underlying the two types of learning might be the same (Heyes, 1994), yet individual learning is assumed to be more costly than social learning as it is time-intensive and thus leads to forgoing other behaviors. Individual learning about novel environments is also risky (Sol \& Lefebvre, 2000), and can lead to injuries or poisoning. However, individual learning has the benefit of providing more exact information than social learning (Boyd \& Richerson, 1988). Juveniles are often found to be more explorative than adults, which enables them to sample their

A.M.P. von Bayern and N.J. Emery share the last authorship

Electronic supplementary material The online version of this article (https://doi.org/10.3758/s13420-019-00383-8) contains supplementary material, which is available to authorized users.

Ira G. Federspiel

ira_federspiel@yahoo.co.uk

1 Sub-Department of Animal Behaviour, Department of Zoology, University of Cambridge, Cambridge, UK

2 Department of Cognitive Biology, Faculty of Life Sciences, University of Vienna, Vienna, Austria

3 Department of Psychology, University of Cambridge, Cambridge, UK
4 Department of Psychotherapy, Bertha von Suttner University, St. Pölten, Austria

5 Behavioural Ecology Research Group, University of Oxford, Oxford, UK

6 Max-Planck-Institute for Ornithology, Seewiesen, Germany

7 Ludwig-Maximilians-Universität München, Planegg-Martinsried, Germany

8 School of Biological and Chemical Sciences, Queen Mary University of London, London, UK 
environment more readily via individual trial-and-error learning (e.g., Australian magpies, Cracticus tibicen (Pellis, 1981); common ravens, Corvus corax, and carrion crows, Corvus corone (Miller, Bugnyar, Pölzl, \& Schwab, 2015); Japanese macaques, Macaca fuscata (Menzel, 1965); and vervet monkeys, Cercopithecus aethiops sabaeus (McGuire, Raleigh, \& Pollack, 1994)).

If a problem cannot be solved via individual trial-and-error learning ("asocial learning" (Heyes, 1994), as an alternative, social learning is often considered the default option for skill acquisition (Laland 2004). Social learning is assumed to be more efficient and less risky (Boyd \& Richerson, 1988). New skills gained through social learning are transferable to novel situations and are thus hypothesized to increase overall cognitive performance (van Schaik \& Burkart, 2011). Social and individual learning can also be combined to acquire new skills (e.g., foraging in orangutans; Jaeggi et al., 2010; Schuppli et al., 2016). In an environment where animals interact with each other on a daily basis, social information is frequently present and available to everyone who is able to perceive and process it ("inadvertent social information"; Danchin, Giraldeau, Valone, \& Wagner, 2004). It is likely that social animals are able to utilize the readily available social information in a group (i.e., "information scrounging"; Giraldeau, Valone, \& Templeton, 2002). For social learning to be successful, a group needs to be comprised of a sufficient number of both information producers and scroungers (Laland, 2004). Those who are successful at using social information from others will experience some advantage over other group members (Russon, 1997; Whiten \& van Schaik, 2007).

Identity and characteristics of the observer(s) and the observed conspecific(s) can further shape the nature of the social interaction (socially biased learning (Fragazy \& Visalberghi, 2004)). For example, observers of a certain age or dominance rank might be more prone to use social information than others (Biro et al., 2003; Langen, 1996), and particular individuals might be more influential demonstrators for some observers than others. Observers might, for example, prefer to copy higher ranking or "expert" individuals (Kendal et al., 2015). Thus, the nature of the relationship between demonstrator and observer can modulate the salience of social information (directed social learning (Coussi-Korbel \& Fragaszy, 1995)). Furthermore, individuals might employ two different social learning strategies; "When" strategies, such as "copy when uncertain" and "Who" strategies, such as "copy the majority" or "copy if better" (Laland, 2004). The "Who" strategies also include copying affiliated, older, or successful individuals, kin or good social learners (e.g., chimpanzees, Pan troglodytes (Biro et al., 2003; Matsuzawa, 1994); magpie-jays, Calocitta formosa (Langen, 1996)). The expected payoff may also influence whether a novel behavior is copied (Vale et al., 2017). Moreover, individuals of low rank might exhibit a bias to copy others (Kendal et al., 2015).
Social learning experiments in the wild contribute greatly to understanding the ecological and evolutionary pressures that might have shaped observed behaviors (Federspiel, Clayton, \& Emery, 2009). Nevertheless, mainly experiments in captivity have so far allowed experimenters to test for social learning within a group under controlled conditions. Such control conditions include testing naïve subjects that were not allowed to observe a demonstrator performing a certain behavior before being tested on that same behavior. Other factors, such as visibility and frequency of the demonstrations or food provision, can also be better controlled in captivity. However, a growing number of social-learning studies run in the field have adopted this "two-action, three-group paradigm," including controls in their design (e.g., Aplin et al., 2015; Gundhold, Whiten, \& Bugnyar, 2014; Thornton \& Malapert, 2009; van de Waal \& Bshary, 2011). One task utilizing this method in captivity was performed on chimpanzees (Whiten, Horner, \& de Waal, 2005). It combined the use of a two-action task (Dawson \& Foss, 1965) within a group setting to create a powerful set-up for testing social learning and cultural processes. Two demonstrators were trained to use one of two alternative tool use techniques and were then reintroduced into their respective group. There, they opened a test apparatus by using one of the two techniques in the presence of their conspecifics. A control group was exposed to the apparatus without a model present. Whereas individuals in the control group failed to solve the task, the novel behaviors seeded by the two demonstrators spread differentially in the two experimental groups. Individuals preferentially used the technique they had observed and that was prevalent within their own group. In a follow-up study, it was found that "ghost conditions," in which the apparatus was operated automatically rather than by a chimpanzee demonstrator, were not sufficient for learning to occur in the chimpanzee observers (Hopper et al., 2007). It therefore seemed that the social stimulus of a conspecific opening the apparatus was vital and that the studies provide support for traditions in chimpanzees. However, this might only be true for complex tasks; simpler tasks may be learned without social information (Hopper, Lambeth, Schapiro, \& Whiten, 2008, 2015).

In some corvids, social information also seems to play a role in the context of foraging. For example, when in close proximity to foraging family members, Florida scrub jays (Aphelocoma coerulescens) learned to forage at a novel food patch (Midford, Hailman, \& Woolfenden, 2000); rooks (Corvus frugilegus) chose to land and forage where others are already foraging (Waite, 1981) and choose the same novel food as a social partner (Dally, Clayton, \& Emery, 2008). Both hooded crows (Corvus cornix) and ravens pick up information about the location of food at roosts that act as "information centers" (Marzluff, Heinrich, \& Marzluff, 1996; Sonerud, Smedshaug, \& Bråthen, 2001); and in experimental studies, ravens that had observed others opening a food box 
approached and opened the box more readily than nonobservers (Fritz \& Kotrschal, 1999). Langen (1996) found evidence for social learning of a novel foraging skill in wild white-throated magpie-jays. Individuals had to open a door in order to gain access to food. Those who had been able to watch trained demonstrators were more likely to acquire the opening skill than those without models. Age and aggression levels affected the social-learning process, in that younger birds were more likely to acquire the technique than older ones and the presence of aggressive animals led to others either refraining from or being encouraged to perform the demonstrated action.

The current study investigates individual and social learning in jackdaws (Corvus monedula) in a semi-naturalistic context. Jackdaws are highly social corvids that form stable pairbonds for life (Roëll, 1978) by food-sharing, which is thought to be involved in the initial formation of bonds by juveniles (von Bayern, de Kort, Clayton, \& Emery, 2007). They roost and forage in large groups, often together with rooks, feed on seeds and insects and, in contrast to most other corvids, do not cache food (de Kort \& Clayton, 2006). Individual levels of agitation influence their anti-predator responses (McIvor, Lee, $\&$ Thornton, 2018). Their socio-cognitive abilities seem to be highly developed and include a pronounced sensitivity to the attentional states of other jackdaws (Davidson, Butler, Fernández-Juricic, Thornton, \& Clayton, 2014; von Bayern \& Emery, 2009a) and even humans (von Bayern \& Emery, 2009b). In studies of social learning in jackdaws, it was found that observers preferentially handled a box (out of two boxes) that the demonstrator had fed from (Schwab, Bugnyar, \& Kotrschal, 2008). By displacing others from food containers, they learned about the location of food (Wechsler, 1988), and when confronted with novel, palatable foods, they were influenced by social cues (Greggor, McIvor, Clayton, \& Thornton, 2016). Risk-taking was pronounced during breeding season; only then did observers follow demonstrators to feed next to a novel object (Greggor, McIvor, Clayton \& Thornton, 2016). Jackdaws preferred an object that had been handled last by a human experimenter (Mikolasch, Kotrschal, \& Schloegl, 2012). Individuals that witnessed another jackdaw obtaining food were more successful at opening a food box and foraging from it than non-observers (Federspiel \& Emery, unpublished data).

For social animals such as jackdaws a more natural method than the common "one-to-one" setting to test social learning is in a group. Creating a set-up that combines the benefits of an ecologically valid scenario with a high level of experimental control, thus we tested the jackdaws in a group setting in captivity. We presented a two-action task (Dawson \& Foss, 1965) to the birds, using a similar procedure to that of the chimpanzee studies (Hopper et al., 2007; Whiten et al., 2005). As such, both demonstration and test sessions were conducted within the group. Two observer groups were tested after having observed a demonstrator causing an apparatus to open by either "lifting" or "pushing." In order to investigate a potential difference in learning abilities between birds of a different age (see, e.g., Langen, 1996, or Biro et al., 2003; Whiten \& Mesoudi, 2008, for a review on experimental designs in social diffusion experiments), the bird groups consisted of either juveniles or adults only.

Our objectives were to explore individual and sociallearning processes in juvenile and adult jackdaws in a controlled but ecologically valid setting. We were aiming to find out: (1) whether juvenile and adult jackdaws differ in their (individual) learning propensity, (2) if jackdaws learn socially in the group setting we used, and (3) what other factors would influence the learning processes. If possible, we wanted to determine the underlying social-learning mechanism.

In more detail, this meant the following: Firstly, we anticipated effects of age on learning, as jackdaws, like other largebrained birds, typically go through an extended exploratory phase as juveniles before becoming neophobic (Katzir, 1981). This switch to becoming more neophobic has also been observed in other corvid species, usually in their first year of life (common ravens (Heinrich, 1995) and carrion crows (Miller et al., 2015)). This has been linked to their ecology. Juvenile ravens and crows become independent from their parents towards the end of their first year of life and disperse to find their own territory. During that time, they have an increased need to learn about their new environment (Cramp \& Perrins, 1994; Miller et al., 2015). Low levels of neophobia and an increased exploration rate enable them to do so. In order to explore potential age differences in jackdaws, we compared the time juvenile and adult observers spent at the apparatus and at the relevant parts of the apparatus from which an opening could be caused (i.e., the experimenter opened the apparatus upon an individual performing one of the two opening techniques; for the sake of brevity, this will be called "an individual causing an opening" hereafter). We also compared differences in latency to touch the apparatus and the number of manipulations of the apparatus and the wooden ball (needed to be manipulated in order to achieve an opening). Finally, we aimed to compare the number of caused openings between juveniles and adults.

Secondly, we expected jackdaws to socially learn to open the apparatus, because they are highly social and utilize social information in finding food. As mentioned above, they have demonstrated the ability to socially learn in an experimental pilot study (Federspiel \& Emery, unpublished data) and showed social attention in other contexts. During their time as juveniles, increased opportunities for social learning also occur (Emery, Seed, \& von Bayern, 2007). Investigating potential social learning, we aimed at comparing the abovementioned durations and latencies between observer groups and the control group. We analyzed fractions of openings (successful manipulations) out of all manipulations over time 
for each individual. Changes in performance would indicate individual rather than social learning taking place. We further planned to look at whether employed opening techniques matched the one demonstrated in each group as this would potentially indicate the social-learning mechanism at play.

Lastly, as individuals will acquire the new behavior, they will become demonstrators themselves. We thus also investigated whether "directed social learning" after Coussi-Korbel and Fragaszy (1995) and Laland's (2004) "Who" strategies apply to jackdaws. We expected characteristics other than age to further shape the social-learning process. To test this, we analyzed if dominance rank influenced how much individuals were present at the apparatus, manipulated the wooden ball or other parts of the apparatus, or observed others causing an opening of the apparatus. We further analyzed whether relative dominance rank, scrounging opportunity, and success (number of openings caused) influenced whether a given individual was observed when causing an opening.

\section{Methods}

\section{Subjects and housing}

Three groups of jackdaws, housed in three different aviaries, participated in this experiment. Two were used as observer groups ( $\mathrm{n}=8$ juveniles; $\mathrm{n}=7$ adults) and one as a control group ( $\mathrm{n}=12$ adults; see Electronic Supplementary Material (ESM) 1). The demonstrator (Dohli) was a female bird (hatched in 2006) who was housed together with the control group (not during the experimental period). The bird was socially bonded with Experimenter 2 (AMPvB), who nursed it back to health after a past injury. The close proximity to Experimenter 2 in experiments was therefore rewarding to the demonstrator. All birds apart from !Khosa and Poldi were hand-raised and all were habituated to the presence of humans. For individual identification, the birds were banded with colored leg rings. The three groups were housed physically separated in different parts of an outdoor aviary measuring $6 \mathrm{~m} \times 5 \mathrm{~m} \times 2.80 \mathrm{~m}$ (juveniles), $10 \mathrm{~m} \times 9 \mathrm{~m} \times 2.80 \mathrm{~m}$ (adults) and $15 \mathrm{~m} \times 9 \mathrm{~m} \times 2.80 \mathrm{~m}$ (control group) and kept according to the guidelines of the University of Cambridge.

The three subsections of the aviary could be separated visually by drawing opaque curtains between them. The aviary was equipped with nest boxes, branches, bushes, perches, poles, rocks, and toys. Food was provided ad libitum after experimental sessions (cereals, cooked rice, curd, dried insects, dry cat food, eggs, various types of fruit, mealworms Tenebrio molitor, and minced beef heart). Water was available at all times. During the experimental phase, mealworms were removed from the maintenance diet to ensure motivation during test sessions. Morio worms (Zophobas morio) were used as a reward during test sessions.

\section{Apparatus and experimental set-up}

All experimental sessions were conducted in the outdoor aviaries. The training of the demonstrator took place indoors out of sight of the other jackdaws. The test apparatus consisted of a wooden box ( $18 \mathrm{~cm}$ wide, $16 \mathrm{~cm}$ deep and $33 \mathrm{~cm}$ high) with a treadle $(5.5 \mathrm{~cm} \times 11 \mathrm{~cm} \times 1.5 \mathrm{~cm})$ mounted horizontally on the front of the apparatus $(5 \mathrm{~cm}$ from the floor and $3 \mathrm{~cm}$ from the left side). A yellow wooden ball (approximately $1 \mathrm{~cm}^{3}$ ) with a wire stuck through the center was attached to the center of the treadle $(6.5 \mathrm{~cm}$ from the edge). The ball could be lifted up $2.5 \mathrm{~cm}$, or, with some force, pushed halfway into the treadle (approximately $0.75 \mathrm{~cm}$ ). Next to the treadle, at the same height and $4 \mathrm{~cm}$ from the right side of the apparatus, a perch (11.5 cm long, $1.5 \mathrm{~cm}$ thick) was attached to the apparatus. This enabled the birds to sit while operating the ball and feed after having successfully caused an opening. A feeder opening $(6 \mathrm{~cm} \times 4.5 \mathrm{~cm} \times 4 \mathrm{~cm})$ was cut out of the center of the apparatus, at the jackdaws' eye-level. The opening to the apparatus could be opened and closed by a wooden panel with a Plexiglas window. It was baited with one piece of Morio worm at a time and in full view of the subjects. The window's movements were operated by Experimenter 1 (IGF) via a remote control (Digital Proportional Radio Control System Zebra 2 AM), which controlled a motor connected to the window on the inside of the apparatus. Lines on the wooden ball and the wire were used as visual cues for Experimenter 1 when operating the remote control. For the Demonstration phase, the apparatus was placed inside a cage $(96 \mathrm{~cm} \times 50 \mathrm{~cm} \times 65$ $\mathrm{cm})$, and the demonstrator was released into the cage through a little door $(20 \mathrm{~cm} \times 30 \mathrm{~cm})$. For the Habituation phase, two slightly different versions of the apparatus were used (see Habituation phase). All sessions were recorded with a video camera (Canon Digital Camcorder, Model MD101 Pal) and a Dictaphone for subsequent analysis.

\section{Procedure}

The study was conducted from November 2008 to January 2009 at the avian cognition station associated with the Max Planck Institute for Ornithology in Starnberg, Germany. To avoid different influences of demonstrator identity (Fragazy \& Visalberghi, 2004) and to ensure that all observers experienced similar demonstrations, the same bird (Dohli) acted as a demonstrator for both groups. The study was divided into

- a demonstrator training phase,

- a habituation phase for observers (juveniles and adults) and non-observers (adults of the control group),

- a demonstration phase consisting of 24 30-min sessions for the juvenile observer group (lifting) and 21 30-min sessions for the adult observer group (pushing) $\cdot$ until each individual had observed at least 30 demonstrations, 
- $\quad$ and a test phase consisting of 20 30-min sessions for all three groups.

\section{Demonstrator training phase}

The demonstrator was gradually "shaped" to open the apparatus: step by step, the bird was first trained to feed freely from the apparatus, then to touch the wooden ball in order to cause an opening, and finally to lift the ball upwards at least $2 \mathrm{~cm}$ (approximately twice the length of the ball itself). As soon as the bird lifted up the ball, Experimenter 1 opened the window of the apparatus via the remote control. When the demonstrator was comfortable with approaching the apparatus and reliably causing openings, it was trained to eat from the apparatus inside the cage.

Training was complete when the demonstrator responded consistently by lifting up the ball (without any preceding explorative actions) and feeding from the apparatus opening straight afterwards. Subsequently, the demonstrator was trained to open the apparatus via pushing downwards. This was conducted in a similar manner, shaping the bird's exploratory pecking behavior into a forceful vertical stabbing movement directed at the centre of the ball, which pushed the ball into the treadle. This action was considered complete when at least a third of the ball had been pushed into the treadle. Some force was needed to achieve this, and the normal exploratory pecking behavior was not sufficient. It took the demonstrator 12 sessions of approximately $20 \mathrm{~min}$ to learn the lifting technique in a consistent manner and ten sessions of approximately $20 \mathrm{~min}$ to learn and exclusively use the pushing technique.

\section{Habituation phase: Observer groups and control group}

Because jackdaws are very neophobic, we needed to habituate them to as many aspects of the experiment as possible before the Test phase. This included the yellow wooden ball, which was attached to the test apparatus as well as the video camera and tripod, the remote control, the cage, and the two versions of the habituation apparatus. The objects were placed into each of the three parts of the aviary in a randomized order and left there until all birds ceased to show neophobic reactions towards them and had all touched the wooden ball. Neophobic reactions in jackdaws are, for example, jumping backwards upon noticing an unknown object.

The two habituation apparatuses differed slightly from the test apparatus: Both of them lacked the treadle with the yellow wooden ball. The functional "open-window" habituation apparatus had a loosely attached window that could easily be pushed inwards; the non-functional "closed-window" habituation apparatus allowed no access to the bait, because the window was blocked. To make the distinction between the two versions more obvious, black tape was stuck on both sides of the feeder opening of the closed-window apparatus. The two versions of the habituation apparatus were presented to all three groups in the same order, starting with the openwindow version. Both apparatuses were baited. The openwindow apparatus was placed into one subsection of the aviary in order to habituate the first group. It was regularly rebaited. As soon as all birds had fed from it, it was removed from the given group and replaced with the closed-window version. This version was also left inside the subsection of the aviary until the birds ceased to show neophobic reactions towards it. The same procedure was followed for the other two groups.

The rationale for using two different types of habituation apparatus was as follows: First, we were aiming for a general neophobia reduction. Also, the birds should learn to feed from the open-window apparatus as a first step. As a second step, we were aiming to have them figure out that they cannot feed freely from the apparatus if there is black tape next to the window of the apparatus. The test apparatus looked like the closed-window habituation apparatus with a treadle and ball attached to it. During the Demonstration phase, we expected the subjects to learn that the apparatus with the black tape can be operated to gain a reward after all: by manipulating the "newly attached" treadle with the ball.

Habituation lasted approximately 1 week in total per group. Within that week, birds ceased to show neophobic reactions to all items, were feeding from the open-window apparatus, and stopped approaching the closed-window apparatus.

\section{Demonstration phase: Observer groups}

The test group was visually isolated from the other groups by drawing the opaque curtains between the subsections of the aviary (see Subjects and housing). The apparatus was placed inside a cage on the ground, and the demonstrator was released into the cage (see Fig. 1).

The observers could watch the demonstrations from the top of the cage, the ground within two body lengths from the cage, or from one of the wooden perches above the cage. The perches were located at distance of approximately $2.70 \mathrm{~m}$ in the juvenile observer group and at $2.50 \mathrm{~m}$ in the adult observer group. A demonstration was only counted as "observed," if the head of the given jackdaw was oriented towards the demonstrator. The birds received approximately 20 blocks of one to ten demonstrations per day, depending on the demonstrator's motivation. The lifting technique was demonstrated to the juveniles, the pushing technique to the adults. Demonstrations were continued until each individual of both groups had observed at least 30 openings and consecutive feeding events. Observed demonstrations were measured from the observers' perspective. A demonstration was counted as "observed" if the head of an individual was turned and tilted towards the demonstrator. We are aware that this does not 

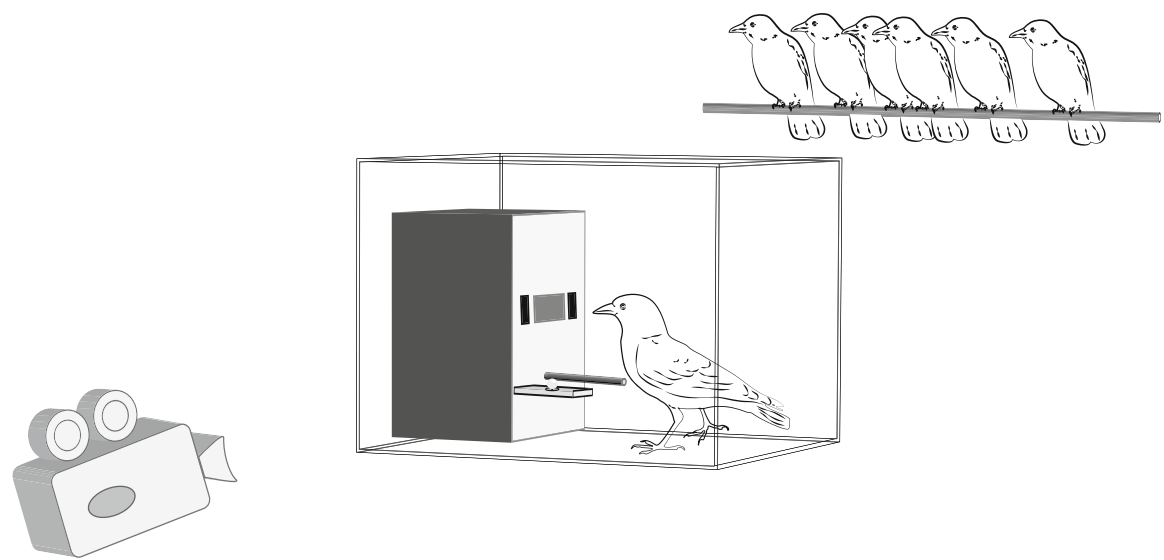

Fig. 1 The set-up for the Demonstration phase, with the demonstrator at the test apparatus inside the cage and observers watching from a perch above (distance to apparatus: approx. $2.70 \mathrm{~m}$ in the juvenile group; $2.50 \mathrm{~m}$ in the adult group)

necessarily mean the demonstration was actually observed; however, at the very least, this method provided us with a more accurate approximation than counting the performed demonstrations (from the demonstrator's perspective). In order to avoid a neophobic response towards the test apparatus and to control for total exposure time, the non-observers (control group) were presented with the test apparatus inside the cage for approximately the same time of exposure as the observer groups.

During demonstration sessions, two experimenters were present: Experimenter 1 sat approximately $2 \mathrm{~m}$ from the cage, operating the video camera, Dictaphone and remote control for the apparatus; Experimenter 2 stayed near the demonstrator in order to keep it relaxed and motivated. She kept her glance focused on the ground, so as not to provide any cues to the observer birds.

\section{Test phase: Observer groups and control group}

Groups were tested during 2030 -min sessions. The set-up was similar to the one of the Demonstration phase. The test group was visually isolated from the other groups, and the test apparatus was placed on the ground at the same spot as during the Demonstration phase. Without the cage, the apparatus was now freely accessible. Experimenter 1 baited and closed the apparatus in the aviary and in sight of the birds. One piece of Morio worm was used at a time. Subsequently, the experimenter opened the window of the apparatus when a bird had performed one of the two correct actions at the yellow ball. The apparatus was re-baited straight after the given bird had swallowed the worm. If no bird approached the apparatus for $5 \mathrm{~min}$, the experimenter pretended to re-bait the apparatus in order to increase motivation. If a bird had achieved at least 40 openings, it was excluded from any further sessions, i.e., physically removed from the group prior to the next test session. Excluded birds were separated in a visually isolated compartment of the aviary for the duration of the test session.
This was done to avoid monopolization of the apparatus by dominant birds.

\section{Establishment of dominance hierarchy}

Daily 20-min observation sessions were conducted over the course of 2 months prior to the experiment. During alloccurrence observations, the frequency and direction of displacements between group members were recorded. Displacements were defined as an animal retreating by at least two body lengths after having been approached by another. Data were then arranged into matrices, and a dominance hierarchy was established. Based on random permutations $(10,000)$ of the displacement matrices, Landau's linearity index $(h)$ was calculated using MatMan 1.0 (Noldus Information Technologies, Wageningen, The Netherlands, 1998). A measure of 1 indicated a linear dominance hierarchy; a measure of 0 indicated a non-linear hierarchy (Appleby, 1983; de Vries, Netto, \& Hanegraaf, 1993; Hemelrijk, 1990). The directional consistency index (dci) showed the consistency of the hierarchy $(1=$ consistent, $0=$ not consistent; for a more detailed description of MatMan 1.0 see de Vries et al., 1993, or MatMan 1.0 manual). Hierarchy calculations were possible for the juvenile observers only. Adult observers and adults of the control group interacted less frequently and, therefore, not enough data were available.

\section{Data analysis}

In the Demonstration phase, we noted which birds observed any given demonstration. The test sessions were scored using defined "states" (times spans) and "events" (individual behaviors). Two sets of mutually exclusive states were included: set 1 for the presence/absence of a bird at the set-up; set 2 for defining where exactly the bird was in relation to the apparatus. Events were scored for behaviors at the test apparatus (see ESM 2). 
Videotapes of experimental sessions were coded using The Observer 5.0 behavioral analysis program (Noldus Information Technology, Wageningen, The Netherlands). Data were analyzed with STATISTICA 7 (StatSoft Inc., 1984-2004) (see ESM 3). Non-parametric statistics were used to analyze the data. All tests were two-tailed, and $\alpha$ was set at 0.05 . Where two or more post hoc tests were performed, we additionally stated Bonferroni adjusted p-values $\left(P^{*}=P^{*} n\right)$. States and events of the three groups were compared with Kruskal-Wallis ANOVAs and/or Mann-Whitney U tests. Adjusted $\mathrm{p}$-values were given for tests including data with two or more ties, i.e., equal values in both groups (Siegel, 1956). The influence of dominance hierarchy on the behavior of our subjects at the apparatus was analyzed with Spearman rank correlations of the ranks with total states and events (sessions 1-7; see ESM 4). The performance over time was analyzed with Spearman rank correlations of the fraction of successful manipulations, i.e., those leading to an opening, with the number of sessions an individual participated in. We further investigated influences of various factors on learning during the Test phase, when new demonstrators became available.

We calculated a generalized linear mixed model (GLMM) with a Poisson distribution and a log-link function in order to examine the influence of the following factors on how many times a demonstrator was observed when causing an opening of the apparatus during the Test phase: kinship (with the observer), the combination of the demonstrator's and observer's sex, total number of scroungings by the observer, the relative dominance rank (observer - demonstrator) and/or total number of openings caused by that demonstrator in the Test phase. Relative rank scores were derived from subtracting the focal animal's rank from the observer's. Therefore, positive scores indicated that in a given dyad, the observer was higher in rank than the demonstrator, whereas negative scores stood for observers lower in rank than demonstrators. We started with the full model comprising the fixed factors listed in Table 1. We included "dyad" and "participated trials" as random factors in order to account for the differences between individuals, their various possible dyadic combinations, and the different number of trials each observer participated in. "Dyad" were all 56 possible dyad combinations in the juvenile observer group. "Participated trials" was defined as the number of trials in which both members of each given dyad were present. A "trial" lasted from the experimenter replenishing the apparatus to an individual removing the reward. To derive the final model, we determined the relative AICc (Akaike Information Criteria with a correction for finite sample sizes) by calculating the difference between each model's AICc and the model with the lowest AICc (Burnham \& Anderson, 2010). Additionally, we calculated Akaike weights ( $w i$ ) representing posterior probabilities of the model used to calculate evidence ratios (Burnham \& Anderson, 2010). Fixed factors are presented in the final model irrespective of their statistical significance (Table 2). Figures were assembled using Adobe Illustrator (Adobe Systems Incorporated; Fig. 1) or Graph Pad Prism (GraphPad Software, Inc.; Figs. 2, 3, and 4).

\section{Results}

\section{Test phase}

\section{Time spent at the apparatus}

Groups differed in the time they spent at the apparatus (within two body lengths; Kruskal-Wallis ANOVA, $H=21.605, N=$ $26, P<0.001 ;$ median juveniles $=2,568.98 \mathrm{~s}$, adults $=275.40$ $\mathrm{s}$, control group $=0 \mathrm{~s}$; Fig. 2). Both observer groups spent more time at the apparatus than the control group (MannWhitney U tests, juvenile group: $Z=3.361, N_{1}=8 N_{2}=8$, $P^{*}=0.016$; adult group: $Z=3.554, N_{1}=10, N_{2}=8, P^{*}=$ 0.018 ). Of the control group, only one individual ever got within two body lengths of the apparatus: Zulu stayed close to the apparatus in session 20 for $6.3 \mathrm{~s}$. Individuals of the juvenile observer group spent more time at the apparatus than members of the adult observer group (Mann-Whitney U test, $Z$
Table 1 Stepwise backward model selection to explain openings watched by the observer (a focal individual) executed by the demonstrator (an observed individual) as a function of kinship, sex combination, scroungings by the observer, relative dominance rank ("hierarchy"), and total openings by the demonstrator

\begin{tabular}{llllllllll}
\hline Variable & Random factors & Fixed factors & F & df1 & df2 & P & AICc & $\Delta$ AICc & $\omega$ \\
\hline Observed openings & Dyad, participated trials & $\begin{array}{c}\text { kin + sexes + scroungings + hierarchy + total } \\
\text { openings by observed individual } \\
\text { kin + scroungings + hierarchy + total openings by } \\
\text { observed individual } \\
\text { scroungings + hierarchy + total openings by } \\
\text { observed individual }\end{array}$ & 3.58 & 7 & 48 & 0.004 & 276.02 & 3.71 & 0.08 \\
& $\mathbf{8 . 5 4}$ & $\mathbf{3}$ & $\mathbf{5 2}$ & $\leq \mathbf{0 . 0 0 1}$ & $\mathbf{2 7 2 . 3 2}$ & $\mathbf{0}$ & $\mathbf{0 . 5 3}$
\end{tabular}

Rankings based on AICc are presented. The model with the lowest Akaike weight $(\omega)$ indicates that its fixed factors explain the response variable's variance best. The final model is highlighted in bold 
Table $2 \mathrm{~F}$ and $\mathrm{t}$ statistics for the final generalized linear mixed model

\begin{tabular}{llllllrrr}
\hline Variable & Factor & F & df1 & df2 & beta & SE & t & p \\
\hline Observed openings & Model & 8.54 & 3 & 52 & -4.02 & 1.192 & -3.372 & $\leq 0,001$ \\
& Scroungings & 5.98 & 1 & 52 & 0.28 & 0.116 & 2.446 & 0.018 \\
& Hierarchy & 3.07 & 1 & 52 & -0.18 & 0.102 & -1.754 & 0.085 \\
& Openings by observed individual & 7.124 & 1 & 52 & 0.06 & 0.021 & 2.669 & 0.01 \\
\hline
\end{tabular}

$=3.199, N_{1}=8, N_{2}=10, P=0.001, P^{*}=0.018$; Fig. 2 ). As the individuals of the control group were almost never present and never touched or looked at the apparatus, their data were excluded from all further analyses.

\section{Time spent at relevant parts of the apparatus}

The juvenile observer group spent more time at the parts of the apparatus from which an opening could be caused than the adult observer group (treadle or perch; Mann-Whitney U tests: overall time: $Z=3.110, N_{1}=8, N_{2}=10, P=0.002$ ).

\section{Latency to approach and touch the apparatus}

The juvenile observer group was faster at getting within two body lengths of the apparatus than the adult group (MannWhitney $\mathrm{U}$ tests, $Z=-2.843, N_{1}=8, N_{2}=10, P=0.004$; median juveniles $=747.9 \mathrm{~s}$, adults $=739.4 \mathrm{~s}$ ). The juvenile observer group was also the first to first touch the apparatus, either by manipulating it, opening it, or sitting on it (MannWhitney U tests, $Z=-3.199, N_{1}=8, N_{2}=10, P=0.001$; median juveniles $=710.3 \mathrm{~s}$, adults $=2338.9 \mathrm{~s}$; Fig. 3 ).

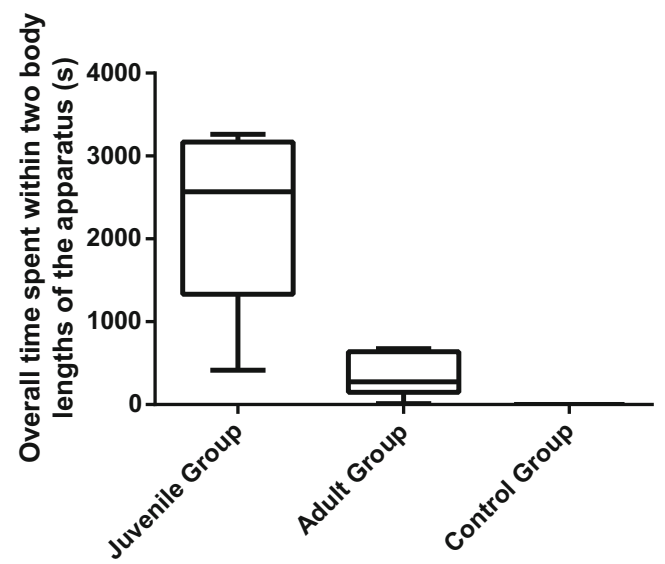

Fig. 2 Box and whisker plots for the total time spent at the apparatus by members of all three groups. Boxes show the interquartile range; the line in the centre of the boxes stands for the median value. Whiskers indicate the largest and smallest value
Total number of actions at the apparatus: Manipulations and openings

The juvenile observers manipulated the apparatus and the yellow wooden ball more often than the adult observer group (Mann-Whitney $\mathrm{U}$ tests with number of actions per duration present, $N_{1}=8, N_{2}=10$ : apparatus: $Z=2.044, P=0.041$; median total number juveniles $=82$, adults $=0$; ball: $Z=3.110$, $P=0.002 ;$ median total number juveniles $=99$, adults $=0)$. All manipulations of the ball were performed with the birds' beaks. Members of the adult observer group never attempted any openings by lifting or pushing and thus never achieved any actual openings. Overall, the juvenile observers caused 256 openings (range per bird $=0-67$, median $=32,95 \%$ confidence intervals $=-17.80 /+72.17)$, almost all of which $(255 /$ 256) were via the "lifting" method that they had observed demonstrated. The first opening was a lift opening that was caused by the highest-ranking bird Mapuche in the first test session, after $12 \mathrm{~m}$ and $31 \mathrm{~s}$. During this time, he had performed 12 manipulations at the apparatus and one ball manipulation. The only push opening was caused by the midranking Heinrich during the 13th session, after having been present at the set-up for a total of $381 \mathrm{~m}$ and $40 \mathrm{~s}$. Before the opening, he had performed 26 manipulations at the apparatus,

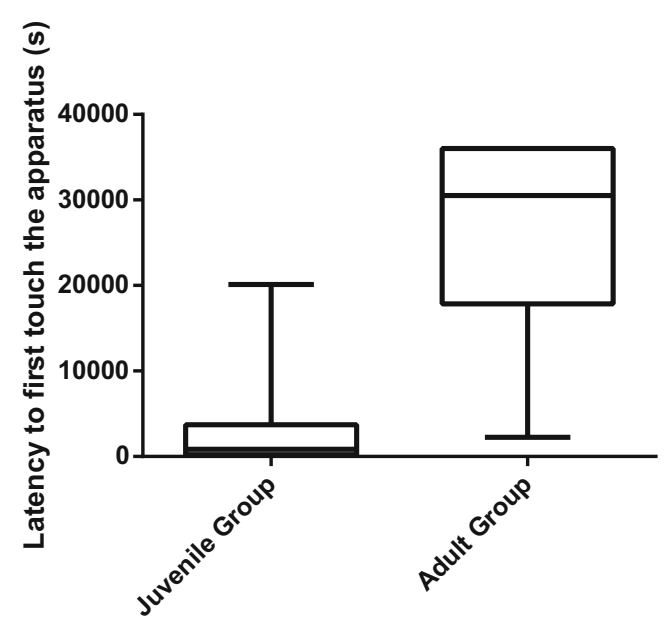

Fig. 3 Box and whisker plots for the latency to touch the apparatus in the two observer groups 


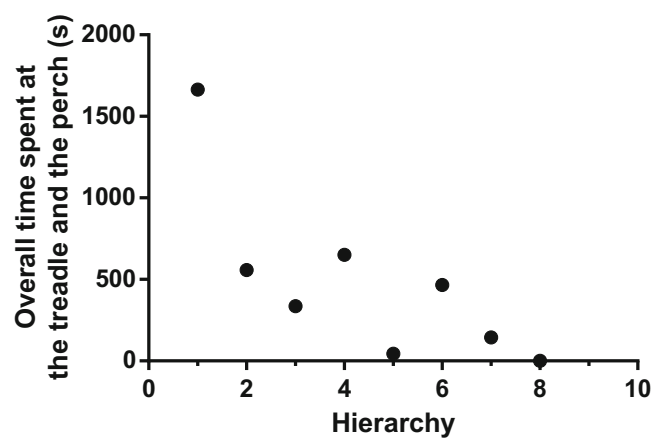

Fig. 4 Scatter plot for the time the animals in the successful juvenile observer group spent at the perch and treadle depending on the hierarchy $(1=$ highest-ranking animal $)$

with 59 of them at the ball. He had observed 22 openings by five different birds, all of which had been lift openings. Apart from Mapuche and Heinrich, four other birds achieved openings, which were also all lift openings. They first opened the apparatus in the first (Kaya), second (Maya), third (Cheyenne), and seventh (Balu) test session, respectively.

Individuals differed in their performance over time. Two of the birds (Balu, Maya) improved their performance over time, one worsened (Kaya), for three we found no effect (Cheyenne, Heinrich, Mapuche), and two never opened the apparatus (Apache, Sioux) (Table 3).

\section{Dominance hierarchy of the juvenile observer group}

Analysis of a total of 154 displacements revealed a stable, linear dominance hierarchy $(h=0.964, d c i=0.935, P<$ 0.001). With Mapuche being the highest in dominance rank, the order was as follows: Mapuche $>$ Balu $>$ Cheyenne $>$ Kaya $>$ Heinrich $>$ Maya $>$ Sioux $>$ Apache.

\section{Factors influencing social-learning opportunities within the juvenile observer group}

The birds that were present at the apparatus most frequently were typically higher-ranking animals, occupying the treadle

Table 3 Results of Spearman rank correlations of the fraction of successful manipulations of the wooden ball (i.e., successful manipulations that led to an opening per overall number of manipulations) and the number of sessions the individual had participated in (juvenile observer group)

\begin{tabular}{llll}
\hline Individual & $N$ & $R$ & $P$ \\
\hline Balu & 15 & 0.760 & $0.001^{\text {**** }}$ \\
Maya & 9 & 0.732 & $0.025^{*}$ \\
Kaya & 6 & -0.812 & $0.050^{*}$ \\
Cheyenne & 7 & 0.473 & n.s. \\
Heinrich & 8 & 0.082 & n.s. \\
Mapuche & 9 & -0.583 & n.s. \\
\hline
\end{tabular}

${ }^{*} p \leq 0.05, * * p \leq 0.01, * * * p \leq 0.001$ and the perch at the apparatus (Spearman rank correlation, $R=$ $-0.786, N=8, P=0.021$; Fig. 4).

Furthermore, higher-ranking animals manipulated the ball more frequently (Spearman rank correlations of frequencies of manipulating the ball, $N=8, R=-0.905, P=0.002)$ and watched more openings caused by others $(R=-0.714, P=$ 0.047). The frequency of an individual (observer) observing another individual (demonstrator) opening the apparatus was best explained by the total number of scroungings by the observer from the demonstrator, the relative dominance rank, and the total number of openings caused by the demonstrator in the Test phase (Table 2). Thus, observers who performed many scroungings also watched the apparatus being opened more often than others. The higher the relative dominance rank, i.e., the difference of rank between the observer and demonstrator, the lower the number of openings that were watched. Thus, lower-ranking individuals tended to watch higher-ranking ones; higher-ranking ones did not seem to watch lower-ranking conspecifics, but rather others of similar rank. Demonstrators that caused a high number of successful openings were watched more often than others (Table 2).

\section{Discussion}

Overall, juvenile and adult jackdaws differed in skill acquisition. This might have been due to a difference in learning propensity and could have been influenced by other factors such as an increased motivation to obtain food in the young. Juveniles spent more time at the apparatus, were more explorative, and caused the apparatus to open. Two findings indicated that jackdaws learned socially in the group setting we used: Both juveniles and adults spent more time at the apparatus than the adults of the control group. In the juvenile observer group, almost all the manipulations at the apparatus matched the demonstrated method. Individual characteristics that further shaped the learning process were dominance rank, scrounging opportunities, and being successful at gaining a reward. The control group did not manipulate the apparatus. Due to the lack of this baseline, it is difficult to determine for certain whether the opening technique was acquired via individual or social learning. If social learning played a role in the current study, it was most likely local or stimulus enhancement that initially drew the jackdaws to the apparatus.

In more detail, we found the following: As hypothesized, juvenile jackdaws were more explorative than adults. This has in the past also been found for two other corvid species, common ravens, and carrion crows. Both species were found to interact with novel objects more frequently as juveniles (Miller et al., 2015). In the current study, jackdaws were faster at touching the apparatus and spent more time at the parts of the apparatus from which an opening could be caused. They also manipulated the apparatus more often than the adults and 
were the only group to ever cause openings. As all groups went through a habituation phase, those differences could not be ascribed to differences in neophobia. The juvenile observers were in their first summer of life and almost 5 years younger than the individuals of the adult observer group. Jackdaws, like most corvids, exhibit slow development and prolonged parental care. Growing up in such a protected environment may enable them to seize all possible learning opportunities and sample their environment to prepare them for later in life. Before becoming neophobic and thus wary of novel objects and changes in their environment (Katzir, 1981), juveniles are hence more likely to discover the solution to a novel problem via individual learning. As stated by Miller et al. (2015), this pattern might be "corvid-general" rather than specific to certain corvid species.

Juveniles also experience increased opportunities for social learning (Emery et al., 2007). We hypothesized that jackdaws would learn socially how to cause an opening of the apparatus, as they have been shown to learn socially in various contexts (Greggor et al., 2016; Schwab et al., 2008; von Bayern \& Emery, 2009b). Both juveniles and adults spent more time at the apparatus than the adults of the control group. Adults of the control group hardly ever approached the apparatus. The fact that the only difference between observers and nonobservers was that the former experienced a social stimulus, suggests that there was a social-learning effect, drawing the attention of the observers to the apparatus.

However, whereas both observer groups readily approached the apparatus from Trial 1, only the juvenile observer group opened the apparatus. One possible explanation for this is that lifting may be easier than pushing. When exploring objects, jackdaws usually peck at them, whereas lifting seems to be a much less prevalent behavior (von Bayern, personal observation). Nevertheless, the pushing technique did require some force, which might not be easy to discover by chance. Unfortunately, the control group did not manipulate the apparatus. Due to this lack of a baseline, the relative similarity of the two actions is difficult to determine. Juvenile observers may have acquired the opening technique by observing the demonstrator during the Demonstration phase or learned the technique via individual or social learning during the Test phase. In order to examine this in more detail, future studies should compare individuals of the same age groups in both social-learning conditions and in the control. Due to the restricted number of available groups this was not possible in the current study.

Alternatively, juveniles may generally be better at social learning or more receptive to social cues than adults. It is thus also possible that a social stimulus is more salient for juveniles than for adults, because they need to acquire skills for later in life during this crucial developmental window. During their cognitive development they may thus be particularly receptive to social-learning opportunities. This was previously observed in other species. When Caracara Chimango raptors (Milvago chimango) were presented with a food box after having observed a conspecific opening it, juvenile observers were more successful and faster than adults at approaching and opening the box to gain a food reward (Biondi, Bó, \& Vassallo, 2010; Biondi, García, Bó, \& Vassallo, 2010). A similar effect was found in a natural corvid group of magpie-jays, where a novel foraging skill was more likely to be acquired by younger birds than older ones (Langen, 1996).

As juveniles acquired the opening technique, they became new demonstrators. Along the lines of Coussi-Korbel and Fragaszy's (1995) "directed social learning" and Laland's (2004) "Who" strategies, we hypothesized that individual characteristics would shape learning processes in jackdaws. This kind of influence was observed for the factor age in house mice (Mus domesticus (Choleris, Guo, Liu, Mainardi, \& Valsecchi, 1997)) and Norway rats (Rattus norvegicus (Galef \& Whiskin, 2004)), kinship in ringdoves (Streptopelia risoria (Hatch \& Lefebvre, 1997)), social status and foraging success in laying hens (Gallus gallus domesticus (Nicol \& Pope, 1999)), familiarity in guppies (Poecilia reticulate (Swaney, Kendal, Capon, Brown, \& Laland, 2001)), sex and feeding activity in zebra finches (Taenopygia guttata (Katz \& Lachlan, 2003)), and affiliation in chimpanzees (Bonnie \& de Waal, 2006). In jackdaws, a previous study showed that the birds preferred to learn from non-affiliated individuals (Schwab et al., 2008).

In the current study, dominant juveniles monopolized the apparatus, which restricted learning opportunities within that group. They spent more time at the apparatus and manipulated the wooden ball more frequently than the lower-ranking individuals. Thus, holding a high rank in the group's hierarchy created the opportunity to monopolize not just food, but also learning opportunities. Observations of successful openings were also shaped by certain factors: The difference in dominance rank between observer and demonstrator, the opportunity to scrounge food, and how successful a given demonstrator was. Lower-ranking individuals tended to watch higherranking ones, higher-ranking individuals preferentially watched conspecifics of similar rank. Such a bias to copy individuals of a certain dominance rank was also found, for example, in chimpanzees (Kendal et al., 2015). Successful individuals were preferentially watched ("knowledgeable" individuals; see "Who" strategies (Kendal et al., 2015; Laland, 2004)), as were individuals that food could be scrounged from. Scrounging was also found to influence social learning in common marmosets (Caldwell \& Whiten, 2003), Florida scrub jays (Midford et al., 2000), and meerkats (Thornton, 2008); however, see Giraldeau and Lefebvre (1987) for contrary results.

We initially set out to determine the underlying sociallearning mechanism in case social learning would take place at all. In the juvenile observer group, most manipulations at 
the apparatus and all but one opening matched the demonstrated method. Simple forms of social learning might have been employed, such as social facilitation (the observer's behavior is influenced by the mere presence of a conspecific that has an influence on the observer's motivation (Zajonc, 1965)), contagious behavior (unlearned, species-specific behavior is "released" upon the sight of others engaged in that behavior (Thorpe, 1956)), or response facilitation, a term that has been used to describe an alternative mechanism to imitation in twoaction tasks (the presence of a conspecific performing an act, which might result in obtaining a reward, increases the probability of an observing individual performing the same action (Byrne, 1994)). We consider mere social facilitation unlikely as the birds were never tested immediately after a demonstration session. Although it is not known how long a facilitation effect could last for and how long the interval between demonstration and tests sessions would have to be in order to rule out facilitation (Hoppitt, Blackburn, \& Laland, 2007), we believe conducting test sessions on the day after demonstration sessions would have introduced a salient delay.

An alternative explanation for our finding is individual trial-and-error learning following an initial effect of stimulus (or local) enhancement by the demonstrator. A similar sequence of events led to the milk-bottle opening of three different parids, where the authors concluded that trial-and-error learning proceeded by stimulus enhancement led to the subsequent spread of the behavior throughout Great Britain (Fisher \& Hinde, 1949; Hinde \& Fisher, 1951). More complex forms of social learning might account for our findings, such as imitation or emulation (a more "sophisticated" version of stimulus or local enhancement, where the outcome or goal of an action is copied, but not the exact actions needed to reach said goal or outcome (Tomasello, 1996; but see also (Whiten \& Ham, 1992)). In imitation, animals learn something about the action sequence that they observe and typically copy that action in a relatively exact way (Federspiel et al., 2009; Whiten, Horner, Litchfield, \& Marshall-Pescini, 2004; Zentall, 2004). We expected that when imitating, observers would apply the same technique as the demonstrator from the first test trial on and subsequently use that technique (almost) exclusively (if successful). If emulation was employed, jackdaws would have been expected to reach the same goal or outcome as the demonstrator from the beginning, potentially with a few intermediate steps. In emulation only the outcome or goal is learned by observers - not the exact action needed to reach that end-state. However, successful jackdaws performed up to 90 manipulations at the apparatus and the wooden ball before they first opened the apparatus. They also continued to manipulate the apparatus and ball after having caused the first opening. Thus, not every manipulation led to a successful opening. Performance over time also differed between individuals. Since the observers did not appear to have understood how to open the apparatus from the first trial, it is likely that they had only learned about the location of the "trigger" from the demonstrator via local or stimulus enhancement. This would also fit with the jackdaws' ecology. Their diet does not include hard-to-access types of food, which means they only need to learn about the location of food, but not how to process it by extractive foraging. Therefore, enhancement seems to be the adequate and sufficient mechanism for their requirements (Federspiel et al., 2009).

Due to the set-up and availability of birds, we were only able to test one juvenile and one adult observer group. We acknowledge that it would have been ideal to test both adults and juveniles with both opening techniques. Future studies should include testing an additional group with a ghost control. This would allow pinpointing the saliency of social influences. We conclude that if social learning played a role in the current study, it was most likely local or stimulus enhancement that initially drew the jackdaws to the apparatus. However, even though both observer groups spent more time at the apparatus than the control group, it is more parsimonious to assume that juvenile birds were more explorative than adults. This could reflect the enhanced need of juveniles to learn about their environment early in life. Also, the lifting technique might have been easier to acquire than pushing. Our findings of individual factors shaping learning opportunities in jackdaws show that these colonial breeding corvids are an interesting model system for studying the dynamics of individual and social learning.

Acknowledgements We appreciate the assembling of Fig. 1 by Nadja Kavcik. We are grateful to The Cambridge European Trust, the Ludgren Fund, the Cambridge Philosophical Society, the Balfour studentship, and Gonville and Caius College, Cambridge for funding to I.G. Federspiel. N. J. Emery was funded by a Royal Society University Research Fellowship. We also thank I. Neumayr and G. Fries for their help with animal caretaking.

\section{References}

Aplin, L. M., Farine, D. R., Morand-Ferron, J., Cockburn, A., Thornton, A., \& Sheldon, B. C. (2015). Experimentally induced innovations lead to persistent culture via conformity in wild birds. Nature, 518, 538-541. https://doi.org/10.1038/nature13998

Appleby, M. C. (1983). The probability of linearity in hierarchies. Animal Behaviour, 31, 600-608.

Biondi, L. M., Bó, M. S., \& Vassallo, A. I. (2010). Inter-individual and age differences in exploration, neophobia and problem-solving ability in a Neotropical raptor (Milvago chimango). Animal Cognition, 13, 701-710. https://doi.org/10.1007/s10071-010-0319-8

Biondi, L. M., García, G. O., Bó, M. S., \& Vassallo, A. I. (2010). Social learning in the Caracara chimango, Milvago chimango (Aves: Falconiformes): an age comparison. Ethology, 116, 722-735. https://doi.org/10.1111/j.1439-0310.2010.01794.x

Biro, D., Inoue-Nakamura, N., Tonooka, R., Yamakoshi, G., Sousa, C., \& Matasuzawa, T. (2003). Cultural innovation and transmission of tool 
use in wild chimpanzees: Evidence from field experiments. Animal Cognition, 6, 213-223.

Bonnie, K. E., \& de Waal, F. B. M. (2006). Affiliation promotes the transmission of a social custom: Handclasp grooming among captive chimpanzees. Primates, 47, 27-34. https://doi.org/10.1007/ s10329-005-0141-0

Boyd, R., \& Richerson, P. J. (1988). Culture and the evolutionary process. Chicago: The University of Chicago Press.

Burnham, K. P., \& Anderson, D. R. (2010). Model selection and multimodel inference: A practical information-theoretic approach. London: Springer.

Byrne, R. W. (1994). The evolution of intelligence. In P. J. B. Slater \& T. R. Halliday (Eds.), Behaviour and evolution. (pp. 223-265). Cambridge, U. K.: Cambridge University Press.

Caldwell, C. A., \& Whiten, A. (2003). Scrounging facilitates social learning in common marmosets, Callithrix jacchus. Animal Behaviour, 65, 1085-1092. https://doi.org/10.1006/anbe.2003.2145

Choleris, E., Guo, C., Liu, H., Mainardi, M., \& Valsecchi, P. (1997). The effect of demonstrator age and number on duration of sociallyinduced food preferences in house mouse (Mus domesticus). Behavioural Processes, 41, 69-77.

Coussi-Korbel, S., \& Fragaszy, D. M. (1995). On the relation between social dynamics and social learning. Animal Behaviour, 50, 14411453.

Cramp, S., \& Perrins, C. B. (1994). The birds of the Western Palearctic. Oxford, UK: Oxford University Press.

Dally, J. M., Clayton, N. S., \& Emery, N. J. (2008). Social influences on foraging by rooks (Corvus frugilegus). Behaviour, 145, 1101-1124.

Danchin, E., Giraldeau, L.-A., Valone, T. J., \& Wagner, R. H. (2004). Public information: From nosy neighbors to cultural evolution. Science, 305, 487-491.

Davidson, G. L., Butler, S., Fernández-Juricic, E., Thornton, A., \& Clayton, N. S. (2014). Gaze sensitivity: Function and mechanisms from sensory and cognitive perspectives. Animal Behaviour, 87, 315.

Dawson, B., \& Foss, B. M. (1965). Observational learning in budgerigars. Animal Behaviour, 13, 470-474.

de Kort, S. R., \& Clayton, N. S. (2006). An evolutionary perspective on caching by corvids. Proceedings of the National Academy of Sciences, 273, 417-423.

de Vries, H., Netto, W. J., \& Hanegraaf, P. L. H. (1993). Matman - A program for the analysis of sociometric matrices and behavioral transition. Behaviour, 125, 157-175.

Emery, N. J., Seed, A. M., \& von Bayern, A. M. P. (2007). Cognitive adaptations of social bonding in birds. Philosophical Transactions of the Royal Society B, 362, 489-505. https://doi.org/10.1098/rstb. 2006.1991

Federspiel, I. G., Clayton, N. S., \& Emery, N. J. (2009). The 3E's approach to social information use in birds: Ecology, ethology and evolutionary history. In D. Reuven \& J. M. Ratcliffe (Eds.), Cognitive ecology II (pp. 272-297). Chicago: University of Chicago Press.

Fisher, J., \& Hinde, R. A. (1949). The opening of milk bottles by birds. British Birds, 42, 347-357.

Fragazy, D., \& Visalberghi, E. (2004). Socially biased learning in monkeys. Learning \& Behavior, 32, 24-35.

Fritz, J., \& Kotrschal, K. (1999). Social learning in common ravens, Corvus corax. Animal Behaviour, 57, 785-793. https://doi.org/10. 1006/anbe.1998.1035

Galef, B. G. J., \& Whiskin, E. E. (2004). Effects of environmental stability and demonstrator age on social learning of food preferences by young Norway rats. Animal Behaviour, 68, 897-902. https://doi.org/ 10.1016/j.anbehav.2003.10.029

Giraldeau, L. A., \& Lefebvre, L. (1987). Scrounging prevents cultural transmission of food-finding behavior in pigeons. Animal Behaviour, 35, 387-394.
Giraldeau, L. A., Valone, T. J., \& Templeton, J. J. (2002). Potential disadvantages of using socially acquired information. Philosophical Transactions of the Royal Society B, 357, 1559-1566. https://doi. org/10.1098/rstb.2002.1065

Greggor, A. L., McIvor, G. E., Clayton, N. S., \& Thornton, A. (2016). Contagious risk taking: Social information and context influence wild jackdaws' responses to novelty and risk. Scientific Reports, 6 , 27764. https://doi.org/10.1038/srep27764

Gundhold, T., Whiten, A., \& Bugnyar, T. (2014). Video demonstrations seed alternative problem-solving techniques in wild common marmosets. Biology Letters, 10, 20140439. https://doi.org/10.1098/rsbl. 2014.0439

Hatch, K. K., \& Lefebvre, L. (1997). Does father know best? Social learning from kin and non-kin in juvenile ringdoves. Behavioural Processes, 41, 1-10. https://doi.org/10.1016/ S0376-6357(97)00022-3

Heinrich, B. (1995). Neophilia and exploration in juvenile common ravens, Corvus corax. Animal Behaviour, 50, 695-704.

Hemelrijk, C. (1990). A matrix partial correlation test used in investigations of reciprocity and other social interaction patterns at group level. Journal of Theoretical Biology, 143, 405-420. https://doi. org/10.1016/S0022-5193(05)80036-0

Heyes, C. M. (1994). Social learning in animals: Categories and mechanisms. Biological Reviews, 69, 207-231.

Hinde, R. A., \& Fisher, J. (1951). Further observations on the opening of milk bottles by birds. British Birds, 44, 393-396.

Hopper, L. M., Lambeth, S. P., Schapiro, S. J., \& Whiten, A. (2008). Observational learning in chimpanzees and children studied through 'ghost' conditions. Proceedings of the Royal Society B, 275, 835840. https://doi.org/10.1098/rspb.2007.1542

Hopper, L. M., Lambeth, S. P., Schapiro, S. J., \& Whiten, A. (2015). The importance of witnessed agency in chimpanzee social learning of tool use. Behavioural Processes, 112, 120-129. https://doi.org/10. 1016/j.beproc.2014.10.009

Hopper, L. M., Spiteri, A., Lambeth, S. P., Schapiro, S. J., Horner, V., \& Whiten, A. (2007). Experimental studies of traditions and underlying transmission processes in chimpanzees. Animal Behaviour, 73, 1021-1032. https://doi.org/10.1016/j.anbehav.2006.07.016

Hoppitt, W., Blackburn, L., \& Laland, K. N. (2007). Response facilitation in the domestic fowl. Animal Behaviour, 73, 229-238. https://doi. org/10.1016/j.anbehav.2006.05.013

Jaeggi, A. V., Dunkel, L. P., van Noordwijk, M. A., Wich, S. A., Sura, A. A., \& van Schaik, C. P. (2010). Social learning of diet and foraging skills by wild immature Bornean orangutans: Implications for culture. American Journal of Primatology, 72, 62-71. https://doi.org/ 10.1002/ajp.20752

Katz, M., \& Lachlan, R. F. (2003). Social learning of food types in zebra finches (Taenopygia guttata) is directed by demonstrator sex and feeding activity. Animal Cognition, 6, 11-16. https://doi.org/10. 1007/s10071-003-0158-y

Katzir, G. (1981). Aspects of social behavior in captive jackdaws Corvus monedula L., University of Cambridge, Cambridge, UK.

Kendal, R., Hopper, L. M., Whiten, A., Brosnan, S. F., Lambeth, S. P., Schapiro, S. J., \& Hoppitt, W. (2015). Chimpanzees copy dominant and knowledgeable individuals: Implications for cultural diversity. Evolution and Human Behavior, 36, 65-72. https://doi.org/10.1016/ j.evolhumbehav.2014.09.002

Laland, K. N. (2004). Social learning strategies. Learning \& Behavior, $32,4-14$.

Langen, T. A. (1996). Social learning of a novel foraging skill by whitethroated magpie-jays (Calocitta formosa, Corvidae): A field experiment. Ethology, 102, 157-166.

Marzluff, J. M., Heinrich, B., \& Marzluff, C. S. (1996). Roosts are mobile information centers. Animal Behaviour, 51, 89-103.

Matsuzawa, T. (1994). Field experiments on use of stone tools by chimpanzees in the wild. In R. W. Wrangham, W. C. McGrew, F. B. M. 
de Waal \& P. Heltne (Eds.), Chimpanzee cultures (pp. 351-370). Cambridge, Massachusetts: Harvard University Press.

McGuire, M. T., Raleigh, M. J., \& Pollack, D. B. (1994). Personality features in vervet monkeys: The effects of sex, age, social status and group composition. American Journal of Primatology, 33, 113. https://doi.org/10.1002/ajp.1350330102

McIvor, G. E., Lee, V. E., \& Thornton, A. (2018). Testing social learning of anti-predator responses in juvenile jackdaws: The importance of accounting for levels of agitation. Royal Society Open Science https://doi.org/10.1098/rsos.171571

Menzel, E. W. (1965). Responsiveness to objects in free-ranging Japanese monkeys. Behaviour, 26(130-150).

Midford, P. E., Hailman, J. P., \& Woolfenden, G. E. (2000). Social learning of a novel foraging patch in families of free-living Florida scrubjays. Animal Behaviour, 59, 1199-1207. https://doi.org/10.1006/ anbe.1999.1419

Mikolasch, S., Kotrschal, K., \& Schloegl, C. (2012). The influence of local enhancement on choice performances in African Grey parrots (Psittacus erithacus) and jackdaws (Corvus monedula). Journal of Comparative Psychology, 126, 399-406.

Miller, R., Bugnyar, T., Pölzl, K., \& Schwab, C. (2015). Differences in exploration behavior in common ravens and carrion crows during development and across social context. Behavioral Ecology and Sociobiology, 69, 1209-1220. https://doi.org/10.1007/s00265-0151935-8

Nicol, C. J., \& Pope, S. J. (1999). The effects of demonstrator social status and prior foraging success on social learning in laying hens. Animal Behaviour, 57, 163-171. https://doi.org/10.1006/anbe.1998.0920

Pellis, S. M. (1981). Exploration and play in the behavioral development of the Australian magpie Gymnorhina tibicen. Bird Behaviour, 3, 37-49.

Reader, S. M., \& Laland, K. N. (2003). Animal innovation. Oxford, UK: Oxford University Press.

Roëll, A. (1978). The social behavior of the jackdaw, Corvus monedula, in relation to its niche. Behaviour, 64, 1-124.

Russon, A. E. (1997). Exploiting the expertise of others. In A. Whiten \& R. W. Byrne (Eds.), Machiavellian intelligence II. Extensions and evaluations. Cambridge: Cambridge University Press.

Schuppli, C., Meulmann, E. J. M., Forss, S. I. F., Aprilinayati, F., van Noordwijk, M. A., \& van Schaik, C. P. (2016). Observational social learning and socially induced practice of routine skills in wild immature orang-utans. Animal Behaviour, 119, 87-98. https://doi.org/ 10.1016/j.anbehav.2016.06.014

Schwab, C., Bugnyar, T., \& Kotrschal, K. (2008). Preferential learning from non-affiliated individuals in jackdaws (Corvus monedula). Behavioural Processes, 79, 148-155. https://doi.org/10.1016/j. beproc.2008.07.002

Siegel, S. (1956). Nonparametric statistics for the behavioral sciences. New York: McGraw-Hill.

Sol, D., \& Lefebvre, L. (2000). Behavioural flexibility predicts invasion success in birds. Animal Behaviour, 63, 495-502. https://doi.org/10. 1006/anbe.2001.1953

Sonerud, G. A., Smedshaug, C. A., \& Bråthen, O. (2001). Ignorant hooded crows follow knowledgeable roostmates to food: Support for the information centre hypothesis. Proceedings of the Royal Society B, 268, 827-831. https://doi.org/10.1098/rspb.2001.1586

Swaney, W., Kendal, J., Capon, H., Brown, C., \& Laland, K. N. (2001). Familiarity facilitates social learning of foraging behavior in the guppy. Animal Behaviour, 62, 591-598. https://doi.org/10.1006/ anbe. 2001.1788

Thornton, A. (2008). Social learning about novel foods by young meerkats. Animal Behaviour, 76, 1411-1421. https://doi.org/10.1016/j. anbehav.2008.07.007

Thornton, A., \& Malapert, A. (2009). Experimental evidence for social transmission of food acquisition techniques in wild meerkats.
Animal Behaviour, 78, 255-264. https://doi.org/10.1016/j.anbehav. 2009.04.021

Thorpe, W. H. (1956). Learning and instinct in animals. London: Methuen.

Tomasello, M. (1996). Do apes ape? In C. M. Heyes \& B. G. Galef, Jr. (Eds.), Social learning in animals: The roots of culture (pp. 319 346). San Diego: Academic Press.

Vale, G. L., Flynn, E. G., Kendal, J., Rawlings, B., Hopper, L. M., Schapiro, S. J., . . . Kendal, R. L. (2017). Testing differential use of payoff-biased social learning strategies in children and chimpanzees. Proceedings of the Royal Society B, 284, 20171751. https:// doi.org/10.1098/rspb.2017.1751

van de Waal, E., \& Bshary, R. (2011). Social-learning abilities of wild vervet monkeys in a two-step task artificial fruit experiment. Animal Behaviour, 81, 433-438. https://doi.org/10.1016/j.anbehav.2010.11. 013

van Schaik, C. P., \& Burkart, J. M. (2011). Social learning and evolution: The cultural intelligence hypothesis. Philosophical Transactions of the Royal Society B, 366, 1008-1016. https://doi.org/10.1098/rstb. 2010.0304

von Bayern, A. M. P., de Kort, S. R., Clayton, N. S., \& Emery, N. J. (2007). The role of food- and object-sharing in the development of social bonds in juvenile jackdaws (Corvus monedula). Behaviour, 144, 711-733.

von Bayern, A. M. P., \& Emery, N. J. (2009a). Bonding, mentalising and rationality. In S. Watanabe, A. P. Blaisdell, L. Huber \& A. Young (Eds.), Rational animals, irrational humans (pp. 287-304). Tokyo: Keio University Press.

von Bayern, A. M. P., \& Emery, N. J. (2009b). Jackdaws respond to human attentional states and social cues in different contexts. Current Biology, 19, 602-606. https://doi.org/10.1016/j.cub.2009. 02.062

Waite, R. K. (1981). Local enhancement for food finding by rooks (Corvus frugilegus) foraging on grassland. Zeitschrift für Tierpsychologie, 57, 15-36.

Wechsler, B. (1988). The spread of food producing techniques in a captive flock of jackdaws. Behaviour, 10, 267-277.

Whiten, A., \& Ham, R. (1992). On the nature and evolution of imitation in the animal kingdom: Reappraisal of a century of research. In J. S. R. P. J. B. Slater, C. Beer \& M. Milinski (Ed.), Advances in the study of behavior (Vol. 21, pp. 239-283). New York: Academic Press.

Whiten, A., Horner, V., \& de Waal, F. B. M. (2005). Conformity to cultural norms of tool use in chimpanzees. Nature, 437, 737-740. https://doi.org/10.1038/nature04047

Whiten, A., Horner, V., Litchfield, C. A., \& Marshall-Pescini, S. (2004). How do apes ape? Learning \& Behavior, 32, 36-52.

Whiten, A., \& Mesoudi, A. (2008). The multiple roles of cultural transmission experiments in understanding human cultural evolution. Philosophical Transactions of the Royal Society B, 363, 34893501. https://doi.org/10.1098/rstb.2008.0129

Whiten, A., \& van Schaik, C. P. (2007). The evolution of animal 'cultures' and social intelligence. Philosophical Transactions of the Royal Society B, 362, 603-620. https://doi.org/10.1098/rstb.2006.1998

Zajonc, R. B. (1965). Social facilitation. Science, 149, 269-274.

Zentall, T. R. (2004). Action imitation in birds. Learning \& Behavior, 32, $15-23$.

Publisher's note Springer Nature remains neutral with regard to jurisdictional claims in published maps and institutional affiliations. 